\title{
Calculation of Diffusion Flows for the Formation of Phases in Alloys Iron-Carbon-Alloying Element
}

\author{
Iron and Steel Institute of Z.I.Nekrasov Academician, Dnipro, 49107, Ukraine, e-mail: office.isi@nas.gov.ua
}

\begin{abstract}
The method of calculation of diffusion flows under phase transformations in alloys iron - carbon - alloying element using the principles of nonequilibrium thermodynamics are developed. The expressions for calculation of cross-factors, motive forces and flows in the Onzager equations for a two-phase thermodynamic system, and an example of using the developed method are given.
\end{abstract} alloys.

Key words: nonequilibrium thermodynamics, phase transformations, diffusion flows, motion equations,

Work arrived to the editor 21.03.2019.; accepted for printing15.06.2019.

\section{Introduction}

The phase transformations into the alloyed ironcarbon alloys are largely related to diffusion of components, foremost to the carbon $[1,2]$. For the analysis of diffusive processes in iron-carbon alloys [3-5] it is possible to use the mathematical methods of nonequilibrium thermodynamics. In general case thermodynamics equalizations of motion look like [3]:

$$
\mathrm{J}_{\mathrm{i}}=\sum_{\kappa=1}^{N} L_{i k} X_{k}(\mathrm{i}=1, . ., \mathrm{N}),
$$

where $\mathrm{J}_{\mathrm{i}}$ are flows; $\mathrm{X}_{\mathrm{k}}$ is thermodynamics forces; $\mathrm{L}_{\mathrm{ik}}=$ $\mathrm{L}_{\mathrm{ki}}$ is kinetic Onsager's coefficients [5]; i, k are numbers of charges (substrate of transfer). Basic motive forces of the phase transformations into non-equilibrium thermodynamics are gradients of chemical potentials $\mu_{\mathrm{i}}$ components of the system [3-5]:

$$
X i=\nabla \mu_{i}
$$

The theory of diffusion in metallic alloys with the vacancy mechanism of migration of atoms was developed of Darken [6]. Basic limitations of this theory are related to the necessity of diagonal matrix of Onsager and condition of equilibrium of concentration of vacancies [7]. In work [8] the considered kinetics of diffusion is in the bimetallic system taking into account the undiagonal coefficients of Onsager's matrix. Thermodynamics potential in this work is presented in a kind:

$$
\mu_{i}=\mu_{i}^{0}=R T \ln \left(\gamma_{i} c_{i}\right),
$$

where is $c_{i}$ - the concentration of element $i$; $\gamma_{i}$ coefficient of activity of element $i$, what it is considered dependency upon one concentration of $\mathrm{ci}_{1}$.
Equation for the diffusive flows of the system contains unknown in general case of coefficients activity of elements and vacancies, and their derivatives for to the concentrations, that extraordinarily makes it difficult being of values of lines and cross coefficients. In work [8] expressions of cross coefficients are found for an ideal solid solution.

Calculation of flows at presence of formation of phases in the system this method is a very hard problem. Therefore at consideration of the interrupted systems, id est systems, that contain a few phases the flows of elements and vacancies pass between that, as thermodynamics forces it is possible to use the eventual final drops of chemical potentials $\left(-\Delta \mu_{\mathrm{i}}\right)[9,10]$. If, for example, as charges of process of graphitization to use two sizes - concentrations of carbon and iron, then, concordantly (1), equations of motion take a look:

$$
\begin{aligned}
& J_{1}=L_{11} X_{1}+L_{12} X_{2} \\
& J_{2}=L_{21} X_{1}+L_{22} X_{2},
\end{aligned}
$$

where $J_{1}$ is a flow of carbon that characterizes speed of process of graphitization; $\mathrm{J}_{2}$ is a flow of iron; $\mathrm{X}_{1}=$ $\left(-\Delta \mu_{\mathrm{Fe}}\right), \mathrm{X}_{2}=\left(-\Delta \mu_{\mathrm{C}}\right)$ is thermodynamics forces of iron and carbon. The final drop of potential between two phases has a sign "+" at his increase, and the flow is directed toward the reduction of potential, so the expression for the forces has a sign "-".

In works $[10,11]$ it is shown that in the complex process with two flows of charges takes place increase of one potential, id est. one process "conducts", and other to the "derivatives". The "derivative" process itself, which is separated from the «leading», is impossible, since thermodynamically it is not expedient.

In the system of equalizations (2) thermodynamics 
force $\left(-\Delta \mu_{\mathrm{Fe}}\right)$ is negative and brakes a process on the whole, diffusion of iron is a process is induced, and leading is diffusion of carbon.

Thus, process of formation of phase (to the carbide, intermetallic) in the triple system Fe - C - X (alloying element), by analogy with the process of graphitization $[10,12]$, must be accompanied by the intensive enough transfer of solid solution (alloyed iron). That provides the possibility of growing in it a phase with a lower density carbide or intermetallic. This condition can be executed as a result of iron flow growing due to cross kinetic coefficient of $\mathrm{L}_{21}$ [10].

At presence of in the triple system of alloying element, for example, chrome, the equalization of motion must contain additional components that characterize diffusion of this element [13]. Theory of phase transformations that is controlled by diffusion, develops successfully, see e.g. works [12-18], however the calculation of diffusive flows on principles of nonequilibrium thermodynamics is not almost examined, because unknown values of cross coefficients. Therefore the actual is remained by the problem of successive theoretical description of diffusive flows phase-to-phase in the triple system $\mathrm{Fe}-\mathrm{C}-\mathrm{X}$ (alloying element).

The aim of work is development of methodology of calculation of diffusive flows, kinetic coefficients and thermodynamics forces in triple alloys as iron - carbon alloying element that is based on principles of nonequilibrium thermodynamics.

\section{Formulation of the problem and basic ratios}

Will consider the process of phase formation in the system $\mathrm{Fe}-\mathrm{C}-\mathrm{X}$ (alloying element). From the point of view of thermodynamics such process is transition from metastable to the stable state with formation of new phase $\mathrm{K}$. Will take into account that in the system $\mathrm{Fe}-\mathrm{C}$ - X (alloying element) is two phases - alloyed $\alpha$ - phase (F) and formed phase $(\mathrm{K})$, the flows of carbon $\left(J_{C}\right)$, iron $\left(J_{F e}\right)$, alloying element $\left(J_{X}\right)$ and vacancies $\left(J_{v}\right)$ (Fig. 1). The flow of vacancies in a formed phase will consider equal to the flow of vacancies in a ferrite.

Will consider that the volume of the system can change in general case, which is why condition of complete equality of streams 0 not executed:

$$
J_{F e}+J_{X}+J_{C}+J_{V} \neq 0 \text {. }
$$

According to (1), the thermodynamic equations for the flows take the form:

$$
J_{F e}=-L_{11} \Delta \mu_{F e}-L_{12} \Delta \mu_{C}-L_{13} \Delta \mu_{X}-L_{14} \Delta \mu_{V}
$$

$$
\begin{aligned}
& J_{C}=-L_{21} \Delta \mu_{F e}-L_{22} \Delta \mu_{C}-L_{23} \Delta \mu_{X}-L_{24} \Delta \mu_{V} \\
& J_{X}=-L_{31} \Delta \mu_{F e}-L_{32} \Delta \mu_{C}-L_{33} \Delta \mu_{X}-L_{34} \Delta \mu_{V}, \\
& J_{V}=-L_{41} \Delta \mu_{V}-L_{42} \Delta \mu_{C}-L_{43} \Delta \mu_{X}-L_{44} \Delta \mu_{V}
\end{aligned}
$$

where $J_{F e}, J_{C}, J_{X}, J_{V}-$ flows of iron, carbon, alloying element and vacancies accordingly. Being base on generals of non-equilibrium thermodynamics, it is possible to find the value of kinetic coefficients, so as it was executed in-process [13]. In the conditions of complete equilibrium $\Delta \mu_{F e}=0, \Delta \mu_{C}=0, \Delta \mu_{X}=0$ and $\Delta \mu_{V}=0$.

However for the linear thermodynamics system there is also possibility of dynamic equilibrium, at that all streams are equal 0 , but some thermodynamics forces in the system do not equal a zero (there are their variations) $[4,13]$. For the first time such an opportunity is considered by the author in the work [12] for the double system, and then for the triple system [13]. Let's consider this possibility for the 4-component thermodynamics system. From equations (5) follows, that near-by an equilibrium, at presence of variations of thermodynamics forces, next terms must be executed:

$$
\begin{aligned}
& J_{F e}=0 \Rightarrow L_{11} \delta \mu_{F e}+L_{12} \delta \mu_{C}+ \\
& +L_{13} \delta \mu_{C r}+L_{14} \delta \mu_{V}=0 \\
& J_{C}=0 \Rightarrow L_{21} \delta \mu_{F e}+L_{22} \delta \mu_{C}+ \\
& +L_{23} \delta \mu_{X}+L_{24} \delta \mu_{V}=0 \\
& J_{X}=0 \Rightarrow L_{31} \delta \mu_{F e}+L_{32} \delta \mu_{C}+ \\
& +L_{33} \delta \mu_{X}+L_{34} \delta \mu_{V}=0 \\
& J_{V}=0 \Rightarrow L_{41} \delta \mu_{F e}+L_{42} \delta \mu_{C}+ \\
& +L_{43} \delta \mu_{X}+L_{44} \delta \mu_{V}=0
\end{aligned},
$$

where by an index $\delta \mu_{i}$ mark concerted variations of thermodynamics forces that provide the dynamic equilibrium of the system.

From the first equalization (6.1) establish a connection between variations of forces:

$$
\begin{aligned}
& \delta \mu_{F e}=-\left(L_{12} / L_{11}\right) \delta \mu_{C}-\left(L_{13} / L_{11}\right) \delta \mu_{X}- \\
& -\left(L_{14} / L_{11}\right) \delta \mu_{V}
\end{aligned}
$$
find:

Substituting (7.1) into equations (6.2) - (6.4), we

$$
\begin{aligned}
& J_{C}=\left(L_{22}-L_{21} L_{12} / L_{11}\right) \delta \mu_{C}+\left(L_{23}-L_{21} L_{13} / L_{11}\right) \delta \mu_{C r}+\left(L_{24}-L_{21} L_{14} / L_{11}\right) \delta \mu_{V}=0 \\
& J_{X}=\left(L_{32}-L_{31} L_{12} / L_{11}\right) \delta \mu_{C}+\left(L_{33}-L_{31} L_{13} / L_{11}\right) \delta \mu_{C r}+\left(L_{34}-L_{31} L_{14} / L_{11}\right) \delta \mu_{V}=0 \\
& J_{V}=\left(L_{42}-L_{41} L_{12} / L_{11}\right) \delta \mu_{C}+\left(L_{43}-L_{41} L_{13} / L_{11}\right) \delta \mu_{C r}+\left(L_{44}-L_{41} L_{14} / L_{11}\right) \delta \mu_{V}=0
\end{aligned}
$$




\section{S.V. Bobyr}

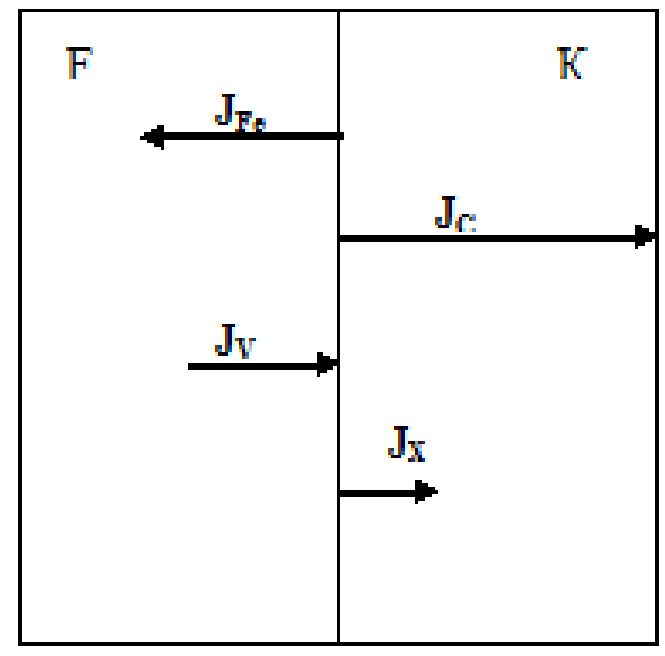

Fig. 1. Scheme of the phase formation (carbide) in the system Fe-C-X (alloying element).

equal 0 coefficients at $\delta \mu_{C}, \delta \mu_{X}$ and $\delta \mu_{V}$, from where it is possible to find the partial decision of the system of equations (6) and (7). For the diagonal components of the system of equations (7.2) - (7.4) it is possible to write down:

$$
L_{i k} L_{k i}=L_{i i} L_{k k}, i, k=1 \ldots 4 .
$$

Taking into account Onsager's ratio, find connection between kinetic coefficients:

$$
L_{i k}=L_{k i}= \pm \sqrt{L_{i i} \times L_{k k}}, i, k=1 \ldots 4,
$$

and the sign in front of the root is selected, coming from the sign (to direction) of the considered flows (see fig. 1). It is possible to make sure a simple substitution, that undiagonal components system of equations (7.2) - (7.4) also transform in 0 . If we choose the sign of "-" for one of cross kinetic coefficients, then signs of other cross coefficients must be consistent. We found a partial resolution systems of equations (6) the same with unknown cross coefficients. Partial resolution (8) of the linear 4-component system of equations (7) it is possible to generalize the component linear thermodynamics system on $\mathrm{N}$, so as a system of equalizations (7) has the same kind for the number of components of $n=$ $2,3,4, \ldots \mathrm{N}$. Therefore and correlation (8) for cross kinetic coefficients is executed at the number of components of $\mathrm{n}=2, \mathrm{~N}$.

Such approach, the same, allows to find cross coefficients in Onsager's equations since direct kinetic coefficients are expected. Thus set connection (8) is executed for the systems not too distant from an equilibrium and for the real system is approximate.

\section{Calculation of thermodynamics forces that operate in system}

Will find general expressions for thermodynamics forces that operate in our system. For an example will use steel of the system Fe-C-Cr from $0.15 \% \mathrm{C}$ and $5 \%$ $\mathrm{Cr}$, that is tempered and released at $600{ }^{\circ} \mathrm{C}$ with formation of the alloyed carbide [13]. Consider that first in hard $\alpha$-solution of this steel there is a chrome with the concentration $C_{C r}=0.05$ and carbon with the concentration of $C_{C}=0.007$, concentration of iron egale $C_{F e}=0.943$. After vacation during a 2 o'clock concentration iron in a solid $\alpha$-solution rises to $C_{F e}^{\prime}=$ 0.9574 , the concentration of chrome goes down to $C^{\prime}{ }_{C r}=$ 0.0425 . In the carbide of cementite as there are a chrome with mass part $\sim 20 \%$ (by the concentration of $C^{K}{ }_{C r}=$ 0.2 ) and carbon with the concentration of $C^{K}{ }_{C}=0.25$, concentration of iron in the carbide $C_{F e}^{\prime}=0.55$. Concentration of vacancies $C v$ in a solid $\alpha$-solution, is equal to $10^{-4}$.

From experimental data it is known that a carbon very quickly (approximately after $1 \mathrm{~min}$ ) retires from $\alpha$ solution of alloy steel at a temperature $550-650{ }^{\circ} \mathrm{C}$ and, thus, formation of the carbidic including predefined, foremost, by diffusion of carbon [19]. Thermodynamics force for a carbon can be expected after the formula [20]:

$$
-\Delta \mu_{C}=-R T \ln \frac{a_{C}^{K}}{a_{C}^{\alpha}},
$$

where $a^{\alpha}{ }_{C}$ is a size of thermodynamics activity of carbon in $\alpha$-solution, $a_{C}^{K}$ is a size of thermodynamics activity of carbon in cementite; $R$ - universal gas constant; $T$ is a temperature of alloy.

Change of thermodynamics activity of carbon in an alloy at alloying his component and it is possible to find on methodology $[20,21]$ from equation:

$$
\ln \left(\mathrm{a}_{\mathrm{C}} / \mathrm{a}_{\mathrm{C} 0}\right)=\beta \mathrm{i} \mathrm{Ni}
$$

where $\beta i$ is a coefficient of influence of element on thermodynamics activity of carbon in an alloy; $N i$ is content of element in an alloy in atomic parts; $a_{C O}$ is thermodynamics activity of carbon for an alloy in the standard state. We will consider that for our steel in the standard state $a_{C O}^{\alpha}=a_{C O}^{K}=a_{C O}$, id est cementite in steel with $0,15 \%$ of $\mathrm{C}$ stable and is in an equilibrium with a solid solution at an endurance temperature $600{ }^{\circ} \mathrm{C}$ [8]. Using this condition and equation (9) and (10), find:

$$
\ln \left(\mathrm{a}^{\mathrm{K}}{ }_{\mathrm{C}} / \mathrm{a}^{\alpha}{ }_{\mathrm{C}}\right)=\beta^{\mathrm{K}}{ }_{\mathrm{Cr}} \mathrm{N}^{\mathrm{K}}{ }_{\mathrm{Cr}}-\beta^{\alpha}{ }_{\mathrm{Cr}} \mathrm{N}^{\alpha}{ }_{\mathrm{Cr}}
$$

The value of $\beta i$ is calculated by the coefficient of the phase distribution of the alloying element $K i=N i(K)$ / $N i(\alpha)$ and the atomic particle of carbon in the $N c$ alloy in the general form $[20,21]$ :

$$
\beta i=-\frac{(K i-1)+(N c(K)-K i N c(\alpha))}{(K i-1) N c+(N c(K)-K i N c(\alpha))}
$$

With a small error for low-alloy alloys it is possible to accept $N c(K)=0,25, N c(\alpha) \approx 0,001$ - to content of carbon in $\alpha$-phase of steel, taken for the diagram of the state of $\mathrm{Fe}-\mathrm{C}$. Using the coefficient of distribution of chrome between $\alpha$-phase and by the carbide of $K_{C r}$, equal 4 , find equation for the calculation of coefficients of influence $\beta_{C r}$ :

$$
\beta_{C r}=-3,246 /(3,0 \mathrm{Nc}+0,246),
$$

where $\beta_{C r}^{\alpha}=-12.16 ; \beta_{C r}^{K}=-3.26$.

Then from the expressions (9), (10) and (11) we can find values:

$$
\begin{gathered}
\ln \left(a^{K}{ }_{C} / a^{\alpha}{ }_{C}\right)=-0,6085+0,652=-0.0425 \\
\text { and }-\Delta \mu_{C}==308,47 \text { Дж. }
\end{gathered}
$$

The work executed at diffusion of carbon from $\alpha$ phase in a carbide is positive. At diffusion of alloying element from solid $\alpha$ - solution in the carbide the 
difference of thermodynamics potentials can be estimated after a formula:

$$
-\Delta \mu_{X}=-R T \ln \frac{a_{X}^{\prime}}{a_{X}}
$$

where $a_{X}$ is a size of thermodynamics activity of alloying element in solid $\alpha$ - solution before the beginning of process, that equals his concentration of $C^{\alpha}{ }_{X}$ approximately; $a_{X}^{\prime}$ is a size of thermodynamics activity of alloying element in solid $\alpha$-solution after completion of process, that equals his concentration of $C^{\prime \alpha}{ }_{X}$ approximately. If an alloying element in our system is a chrome, then $a_{C r}=C_{C r}^{\prime}$ and $a_{C r}^{\prime}=C_{C r}^{\prime}$. At diffusion of chrome from solid $\alpha$ - solution in a carbide find the difference of thermodynamics potentials after a formula:

$-\Delta \mu_{C r}=-R T \ln \frac{{ }^{\prime} C r}{{ }^{a} C r}=-7258 \ln \frac{0,0425}{0,05}=1,180$ кДж.

In work [13] for chrome the difference of thermodynamics potentials was expected after his activity at a carbide. The same value of thermodynamics force was got, as well as it is expected after a formula (16). For diffusion of iron the difference of thermodynamics potentials can be expected from data of change to the concentration of iron from the initial concentration of $C_{F e}(0.943)$ to the final concentration of $C_{F e}^{\prime}$ (stable state) [10]. From experimental data and thermodynamics of process it is known that diffusion of carbon conducts, diffusion of chrome accompanies diffusion of carbon, and diffusion of iron forces, directed towards an increase in iron concentration in ferrite of steel [10]. A final concentration of $C_{F e}^{\prime}$ is concentration of iron in steel on completion of process of formation of phase. Then the difference of thermodynamics potentials for iron find after a formula:

$$
-4 \mu_{F e}=-R T \ln \frac{C_{F e}^{\prime}}{C_{F e}}=-7258 \ln \frac{0.9574}{0.943}=-16,7 \text { Дж, }
$$

And in the end, for the difference of thermodynamics potentials of vacancies also just formula, similar (17) [15]:

$$
-\Delta \mu_{V}=-R T \ln \frac{C_{V}^{\prime}}{C_{V}},
$$

where $C^{\prime}{ }_{V}$ is an unknown value of concentration of vacancies for completion of process. In-process [12] it values for the process of graphitization found from additional physical suppositions for the process of diffusion of vacancies - its stationary or equilibrium thermodynamic forces. The value of thermodynamics force for vacancies in our case will be expected below from additional physical supposition about invariability of volume of alloy on the initial stage.

\section{Calculation of kinetic coefficients and flows}

Taking into account the got correlations will find the value of kinetic coefficients in equations of Онзагера. As known $[4,10]$, direct kinetic coefficients of Lii related to the diffusion coefficients $D i$ by correlation:

$$
\mathrm{L}_{\mathrm{ii}}=\mathrm{C}_{\mathrm{i}} \mathrm{D}_{\mathrm{i}} / \mathrm{RT} \text {, }
$$

where $C_{1}$ is a concentration of iron in an alloy $(0,943) ; C_{2}$ is a concentration of carbon in an alloy $(0,007) ; C_{3}$ is a concentration of chrome in an alloy $(0,05)$.

Dependences of coefficients of diffusion of chrome and carbon in the ferrit alloyed by a chrome from a temperature it is looked like:

$$
\begin{gathered}
D_{F e}^{\alpha}=2,910^{-4} \exp \left[\frac{-251000}{R T}\right] \mathrm{sm}^{2} / s[22], \\
D_{C}^{\alpha}=0,177 \exp \left[\frac{-88230}{R T}\right] \mathrm{sm}^{2} / s[1],
\end{gathered}
$$

$$
D_{C r}^{\alpha}=3,05 \exp \left[\frac{-358000}{R T}\right] \mathrm{sm}^{2} / s \text { [22]. }
$$

At a temperature of $600^{\circ} \mathrm{C}$ :

$$
\begin{aligned}
& D_{1}=D^{\alpha}{ }_{F e} \approx 3.03 \cdot 10^{-19} \mathrm{sm}^{2} / \mathrm{s} ; \\
& D_{2}=D^{\alpha}{ }_{C} \approx 1.0210^{-6} \mathrm{sm}^{2} / \mathrm{s} ; \\
& D_{3}=D^{\alpha}{ }_{C r} \approx 1.3810^{-21} \mathrm{sm}^{2} / \mathrm{s} .
\end{aligned}
$$

Value direct kinetic coefficient for vacancies with the sufficient degree of accuracy will find on next considerations. Will consider flows in $\alpha$-phase in ideal case - to formation of additional phase and their cooperation. The volume of the system here unchanging, which is why for flows in $\alpha$-phase equation is executed:

$$
\mathrm{J}_{\mathrm{Fe}}+\mathrm{J}_{\mathrm{Cr}}+\mathrm{J}_{\mathrm{V}}=0 \text {. }
$$

So as equation (21) is executed at the arbitrary values of thermodynamics forces of iron and chrome, then get the ratio by direct coefficients:

$$
L_{44}=-L_{11} \operatorname{sign}\left(-\Delta \mu_{F e}\right)-L_{33} \operatorname{sign}\left(-\Delta \mu_{C r}\right),
$$

where sign $\left(-\Delta \mu_{F e}\right)$ and sign $\left(-\Delta \mu_{C r}\right)$ is signs of corresponding thermodynamic forces.

Using correlation (8), (19) and (22), find the value of kinetic coefficients for our system: $L_{11}=0.394 \times 10^{-22}$; $L_{22}=0.984 \times 10^{-13} ; L_{12}=-1.97 \times 10^{-17} . L_{33}=0.95 \times 10^{-26}$; $L_{13}=-0.611 \times 10^{-24} . L_{23}=0.306 \times 10^{-19} . L_{44}=0.393 \times 10^{-22}$. $L_{14}=-0.3935 \times 10^{-22} ; L_{24}=1.97 \times 10^{-17} ; L_{34}=0.611 \times 10^{-24}$.

Equaation (21) allows to us to find the value of thermodynamics force for vacancies. if thermodynamics forces of iron (17) and alloying element are known 16). Find the simple substitution of values of thermodynamics forces and kinetic coefficients:

$-\Delta \mu_{V}=\left(-L_{11}\left(-\Delta \mu_{F e}\right)-L_{33}\left(-\Delta \mu_{C r}\right)\right) / L_{44}=116.71$ Дж.

The value of thermodynamics force for vacancies almost equals the value of thermodynamics force of iron with the sign of "-" because contribution of chrome to compatible diffusion on a few orders below than iron. Thus the system of equalizations (5) acquires a kind: 


$$
\begin{gathered}
J_{F e}=0.394 \times 10^{-22}\left(-\Delta \mu_{F e}\right)-1.97 \times 10^{-17}\left(-\Delta \mu_{C}\right)-0.611 \times 10^{-24}\left(-\Delta \mu_{C r}\right)-0.3935 \times 10^{-22}\left(-\Delta \mu_{V}\right) . \\
J_{C}=-1.97 \times 10^{-17}\left(-\Delta \mu_{F e}\right)+0.984 \times 10^{-13}\left(-\Delta \mu_{C}\right)+0.306 \times 10^{-19}\left(-\Delta \mu_{C r}\right)+1.97 \times 10^{-17}\left(-\Delta \mu_{V}\right) . \\
J_{C r}=-0.611 \times 10^{-24}\left(-\Delta \mu_{F e}\right)+0.306 \times 10^{-19}\left(-\Delta \mu_{C}\right)+0.95 \times 10^{-26}{ }_{\left(-\Delta \mu_{C r}\right)+0.611 \times 10^{-24}\left(-\Delta \mu_{v}\right) .} \\
J_{v}=-0.3935 \times 10^{-22}\left(-\Delta \mu_{F e}\right)+1.97 \times 10^{-17}\left(-\Delta \mu_{C}\right)+0.611 \times 10^{-24}\left(-\Delta \mu_{c r}\right)+0.393 \times 10^{-22}\left(-\Delta \mu_{V}\right)
\end{gathered}
$$

In equations (24) well-known values of all thermodynamics forces that operate in the system. From the system of equations (24) follows. that the values of flows of iron. chrome and vacancies substantially grow through the large values of cross coefficients of $L_{12}$. $L_{32}$. $L_{42}$ and considerable size of thermodynamics force $\left(-\Delta \mu_{C}\right)$. Size of carbon flow that has a positive sign determined mainly by the own coefficient of $L_{22}$. Direct calculations allow to us to find the size of diffusive flows on the initial stage of formation of additional phase:

$$
\begin{gathered}
J_{F e}=-6.08 \times 10^{-15} \mathrm{sm}^{2} / \mathrm{s} . J_{C}=3.04 \times 10^{-11} \mathrm{sm}^{2} / \mathrm{s} . \\
J_{C r}=0.94 \times 10^{-17} \mathrm{sm}^{2} / \mathrm{s} . J_{V}=6.07 \times 10^{-15} \mathrm{sm}^{2} / \mathrm{s} .
\end{gathered}
$$

As it possible to see in case of cooperation of flows equation (21) is also executed. So as a flow of chrome has a considerably less size than flow of iron then the flow of vacancies has the same size as flow of iron practically with the sign of "-".

Thus in article methodology of calculation of diffusive flows offers at presence of two phases in alloys iron - carbon - alloying element with the use of principles of non-equilibrium thermodynamics. That allows to expect both lines and cross coefficients in equations. Formulas over of calculation of thermodynamics forces are in work brought in the system Fe-C-X (to alloying an element) - for iron. alloying element of substitution chrome. of element of introduction - carbon and vacancies.

Bobyr S.V. - Ph.D, Senior Researcher, Leading Researcher. Department of Thermal Treatment of Metal for Mechanical Engineering.

[1] G.V. Kurdjumov. L.M. Utevskij. R.I. Jentin. Prevrashhenija v zheleze i stali (Nauka. Moskva. 1977).

[2] P.I. Mel'nik. Diffuzionnoe nasyshhenie zheleza i tverdofaznye prevrashhenija v splavah (Metallurgija. Moskva.1993).

[3] I. Prigozhin. Vvedenie v termodinamiku neobratimyh processov (Inostrannaja literatura. Moskva. 1960).

[4] S. de Groot. P. Mazur. Neravnovesnaja termodinamika (Mir. Moskva. 1964).

[5] L. Onsager. Phys. Rev.. 37. 405 (1931).

[6] L. Darken. Trans. AIME. 175. 184 (1948).

[7] N.B. Borovskij. K.P. Gurov. I.D. Marchukov. Ju.Je. Ugaste. Processy vzaimnoj diffuzii v splavah (Nauka. Moskva. 1973).

[8] V.S. Eremeev. FMM 1978. 45(1). 19 (1978).

[9] A.I. Vejnik. Termodinamika (Vyshejshaja shkola. Minsk. 1968).

[10] A.A. Zhukov. R.L. Snezhnoj. Diffuzionnye processy v metallah (Naukova dumka. Kiev. 1966).

[11] M.A. Krishtal. A.A. Zhukov. R.L. Snezhnoj. Je.G. Titenskij. Termodinamika. fizicheskaja kinetika strukturoobrazovanija i svojstva chuguna i stali. Vyp.4. (Metallurgija. Moskva. 1971).

[12] S.V. Bobyr'. Metallofiz. novejshie tehnol. 35(2). 35 (2013).

[13] S.V. Bobyr'. Metallofiz. novejshie tehnol. 36(10). 1385 (2014).

[14] B.Ja. Ljubov. Kineticheskaja teorija fazovyh prevrashhenij (Metallurgija. Moskva. 1969).

[15] B.S. Bokshtejn. Diffuzija v metallah (Metallurgija. Moskva. 1978).

[16] V. Vovk. G. Schmitz. and R. Kirchheim. Phys. Rev.. 69. 104102 (2004).

[17] N.V. Storozhuk. A.M. Gusak. Metallofiz. novejshie tehnol. 3(8). 34 (2012).

[18] Ju.O. Ljashenko. L.Sh. Gladka. I.O. Shmatko. O.A. Shmatko. Metallofiz. novejshie tehnol. 34(12). 34 (2012).

[19] S.Z. Bokshtejn. Struktura i mehanicheskie svojstva legirovannoj stali (Metallurgizdat. Moskva. 1954).

[20] G.I. Sil'man. Zhurnal fizicheskoj himii 57(2). 57 (1985).

[21] G.I. Sil'man. MiTOM (1). 5 (2002).

[22] L.N. Larikov. V.I. Isajchev. Diffuzija v metallah i splavah. Spravochnik (Naukova dumka. Kiev. 1987). 


\title{
С.В. Бобирь
}

\section{Розрахунок дифузійних потоків при утворенні фаз в сплавах залізо - вуглець - легуючий елемент}

\author{
Інститут чорної металургї ім. 3.І. Некрасова НАН Украӥни. 49107. Дніпропетровськ. Україна. \\ e-mail: office.isi@nas.gov.ua
}

Розроблена методика розрахунку дифузійних потоків при фазових перетвореннях в сплавах залізовуглець-легуючий елемент з використанням принципів нерівноважної термодинаміки. Наведено вирази для розрахунку перехресних коефіцієнтів. рушійних сил та потоків в рівняннях Онзагера для двофазної термодинамічної системи. викладено приклад використання розробленої методики.

Ключові слова: нерівноважна термодинаміка, фазові перетворення, дифузійні потоки. рівняння руху, сплав. 